\title{
AVANCES Y MEJORAS DEL MARCO NORMATIVO PARA LA ASISTENCIA Y PROTECCIÓN DE LOS DESPLAZADOS INTERNOS EN ÁFRICA
}

\author{
María Cervera VallterRA* \\ Profesora Contratada Doctora \\ Universidad de Valencia
}

SUMARIO: 1. ALGUNAS ACLARACIONES PREVIAS.-1.1. Los refugiados.-1.2. Los desplazados internos.-2. LOS DESPLAZADOS INTERNOS EN EL DERECHO INTERNACIONAL.-3. LA RESPONSABILIDAD DE PROTEGER APLICADA A LOS DESPLAZAMIENTOS INTERNOS.-4. LA LABOR DE LA CONFERENCIA INTERNACIONAL DE LA REGIÓN DE LOS GRANDES LAGOS REFERIDA A LOS DESPLAZADOS INTERNOS.-5. PERSPECTIVAS DE FUTURO Y CONSIDERACIONES FINALES: LA CONVENCIÓN DE LA UNIÓN AFRICANA PARA LA PROTECCIÓN Y LA ASISTENCIA DE LOS DESPLAZADOS INTERNOS EN ÁFRICA (CONVENCIÓN DE KAMPALA).

Acercarse a la realidad de la República Democrática del Congo y a los países de su entorno tiene particular interés debido a que esta área geográfica experimentó un importante movimiento de personas a raíz especialmente del genocidio de Ruanda de 1994. Los desórdenes producidos también en otros Estados limítrofes, como Burundi y Uganda, tiene su interés ya que en esta zona de los Grandes Lagos se dio una situación socioeconómica y una catástrofe humanitaria de proporciones gigantescas.

Pasados los años, la situación en estos países, aunque más apaciguada por los conflictos directos, sigue siendo compleja y llena de nuevos hechos. En bue-

\footnotetext{
* Este trabajo ha sido realizado en el marco del Proyecto de investigación «Gobernanza ambiental, instrumentos jurídicos internacionales y economía verde: la Conferencia de Río +20 y más allá», DER2010-34888 del Ministerio de Economía y Competitividad.
} 
na parte de estos territorios - al menos al este de la República Democrática del Congo-, la situación de los desplazados internos y de los refugiados es todavía preocupante sobre todo por la incesante violencia sexual y por el reclutamiento de niños soldado. La preocupación se debe también a que la situación de los desplazados internos y los refugiados de la zona se ha entremezclado con conflictos agrarios y disputas sobre el derecho de pastoreo o de pesca. Además, precisamente en estos lugares y en los campos de refugiados y de desplazados internos, están presentes grupos armados y paramilitares, infiltrados o no, que no han dejado de aspirar a asumir de facto el control del territorio, dándose así violaciones masivas y constantes del Derecho internacional de los derechos humanos y del Derecho internacional humanitario. Por ejemplo, en la República Democrática del Congo, aunque se ha hecho un gran esfuerzo y se ha logrado que gran parte de los miembros de estos grupos armados se incorporen al ejército nacional congoleño, no es extraño que sean estas personas las que sigan cometiendo abusos y vulneraciones del Derecho internacional de los derechos humanos y del Derecho internacional humanitario sobre sus propios nacionales y sobre los refugiados instalados en el país. Los grupos beligerantes no están en guerra con otros ejércitos nacionales, pero dirigen su acción bélica contra la población civil para humillarla y desmoralizarla, sembrando el terror en las zonas en las que operan. Lamentablemente, la ayuda humanitaria para esta población civil a veces es insuficiente o no llega, por la impenetrabilidad de las zonas de acogimiento y de refugio. Lo más desalentador es que todo este panorama se produce aprovechando una gran impunidad y un aparato estatal tan débil y corrupto que da lugar a un limitado control sobre parte del territorio por parte de las autoridades nacionales correspondientes. A ello, se suma la depredación de los ricos recursos naturales y minerales de la zona que siguen sirviendo, bien como moneda de cambio a una población paupérrima que se limita simplemente a sobrevivir, bien en otros casos se emplea como arma de guerra por parte de los grupos armados para perpetuar un clima constante de terror y no perder su hegemonía. Como en un círculo vicioso, este escenario retroalimenta y pone en peligro una gran inestabilidad económica y social y una paz sumamente volátil, en zonas a veces imperceptibles y casi impenetrables del este de la República Democrática del Congo.

A tales efectos, en este trabajo se va a analizar la reacción a estos hechos por parte de dos Organizaciones Internacionales que operan en África, por su honda preocupación y por su serio compromiso en dar respuesta a la situación migratoria en esta parte del mundo. De un lado, se van a detallar las aportaciones de la Conferencia Internacional de la Región de los Grandes Lagos (CIRGL) ${ }^{1}$, creada ad hoc. De otro lado, no se va a olvidar reflexionar sobre los avances efectuados bajo los auspicios de la renovada Unión Africana $(\mathrm{UA})^{2}$ —heredera de la otrora Organización de la Unión Africana (OUA) — y sobre todo las mejoras que para este continente puede significar la adopción de la Convención para la protección y la asistencia de los desplazados inter-

\footnotetext{
1 Véase http://www.icglr.org/.

2 Véase http://www.au.int/fr/.
} 
nos, conocida como Convención de Kampala, adoptada en octubre de 2009 y en vigor desde el 6 de diciembre de $2012^{3}$, a la que dedicaremos la parte final como una etapa de desarrollo como posible solución a los problemas que experimentan los desplazados internos en África, continente especialmente afectado por este problema.

\section{ALGUNAS ACLARACIONES PREVIAS}

Tras el final de la Guerra Fría, en esta región meridional de África han proliferado guerras civiles y crisis políticas y económicas continua, sistemática y recurrentemente. Los hechos ocurridos allí han causado un flujo migratorio de civiles que se han visto obligados a huir de su lugar de residencia habitual y vagar sin rumbo fijo para salvar sus vidas o para evitar violaciones del Derecho internacional de los derechos humanos y del Derecho internacional humanitario. Esta dinámica ha determinado la existencia de dos tipos de personas en una situación parecida pero con un régimen jurídico diferente. De una parte, están aquellas personas que deciden atravesar las fronteras internacionales, en cuyo caso hablamos de «refugiados». De otra parte, están aquellas personas que permanecen en el interior del propio país del que son nacionales, en cuyo caso entramos en la categoría de los «desplazados internos» ${ }^{4}$.

\subsection{Los refugiados}

La situación de los refugiados ha sido tratada profusamente por el Derecho internacional. A modo de recordatorio, los refugiados son aquellas personas que se han visto obligadas a abandonar su país por determinadas causas concretas y, por ello, deciden cruzar la frontera para instalarse en otro. El Convenio de Ginebra, de 28 de julio de 1951, sobre los refugiados ${ }^{5}$ regula la

3 Sobre este convenio, veáse Zorzi GiUstiniani, F., «New Hopes and Challenges for the Protection of IDPs in Africa: The Kampala Convention for the Protection and Assistance of Internally Displaced Persons in Africa», Denver Journal of International Law and Policy, 39, 2011, núm. 2, pp. 347-370.

${ }_{4}$ Se calcula que el 1 por 100 de la población mundial se encuentra en esta situación. Debido a las consecuencias provocadas por el cambio climático se prevé que el desplazamiento de personas sea mucho más amplio en un futuro no muy lejano.

Sobre los desplazados internos, véanse, in extenso, BoAno, C., ZetTer, R. y Morris, T., Environmentally Displaced People: Understanding the linkages between Environmental Change, Livelihoods and Forced Migration, Oxford, University of Oxford, Refugee Studies Center, 2008; KIDANE, W., «Managing Forced Displacement by Law in Africa: The Role of the New African Union IDPs Convention», Vanderbilt Journal of Transnational Law, 44/1, 2011, pp. 1-85; Mooney, E., "Principles of Protection for Internally Displaced Persons», International Migration, 38, 2000, pp. 81-101; MULUGETA ABEBE, A., "Special rapporteurs as law makers: the developments and evolution of the normative framework for protecting and assisting internally displaced persons», The International Journal of Human Rights, 15/2, 2011, pp. 286 y ss.; PonTe IgLesias, M. T., «Un marco normativo e institucional para los desplazados internos en el Derecho internacional», Revista Española de Derecho Internacional, 52, 2000, pp. 49-81; SolÀ Pardell, O., «Desplazados medioambientales. Una nueva realidad», Cuadernos Deusto de Derechos Humanos, 66, Bilbao, Universidad de Deusto, 2012.

5 La Convención entró en vigor el 22 de abril de 1954, cuando se alcanzaron las seis ratificaciones exigidas por el art. 43 . 
situación de estas personas. Junto a él, el 31 de enero de 1967 se adoptó un Protocolo sobre el Estatuto de los refugiados, hecho en Nueva York.

El Convenio de 1951 es el primer texto jurídico en el que se desplegaron importantes esfuerzos para otorgar valor convencional al listado de los derechos humanos de la Declaración Universal de las Naciones Unidas proclamado el 10 de diciembre de $1948^{6}$. Este tratado nació con los primeros intentos de impulsar los esfuerzos de humanización del Derecho internacional en el seno de la ONU. El Convenio de Ginebra especifica las obligaciones jurídicas de protección a favor de personas desprotegidas a cargo de un Estado diferente del de su propia nacionalidad. Este convenio está relacionado con la creación del Estatuto del Alto Comisionado de Naciones Unidas para los Refugiados (ACNUR), que pretendía generalizar una institución —la de los refugiados-, hasta ese momento limitada geográfica y materialmente, es decir, cuando se concedía dicha protección de forma específica ratione personae. Este tratado quiso dar respuesta sobre todo a la situación legada por la Segunda Guerra Mundial en el continente europeo. A partir de entonces se suprimió el criterio de la nacionalidad y del origen de las personas afectadas. Es ésta una tendencia que culminó con la adopción del Protocolo de 1967, en el que se eliminaron por completo las limitaciones temporales y geográficas. Se concretó así la aplicación personal del estatuto y de su contenido, esto es, los derechos y obligaciones de los Estados parte en relación con estas personas vulnerables. Por eso, el Convenio de 1951 limita la tradicional institución del asilo político para objetivar la noción de refugiado.

El apartado A(2) del art. 1 del Convenio de Ginebra define al refugiado como aquella persona que:

«Debido a fundados temores de ser perseguida por motivos de raza, religión, nacionalidad, pertenencia a determinado grupo social u opiniones políticas, se encuentre fuera del país de su nacionalidad y no pueda o, a causa de dichos temores, no quiera acogerse a la protección de tal país; o que careciendo de nacionalidad hallándose, a consecuencia de tales acontecimientos, fuera del país donde antes tuviera su residencia habitual, no pueda o, a causa de dichos temores, no quiera regresar a él».

La definición tiene su importancia cuando los países y las organizaciones gubernamentales y no gubernamentales intentan precisar quién es refugiado y quién no lo es. Las causas de persecución deben coincidir con uno de los siguientes motivos: raza, religión, nacionalidad o pertenencia a un grupo social determinado u opiniones políticas. Como hemos dicho anteriormente, la situación de los refugiados está regulada por el Derecho internacional desde hace algún tiempo y determina el sometimiento a sus potenciales destinatarios a un procedimiento que se concreta en la solicitud de protección o asilo en Estados extranjeros tal y como establece el Convenio de 1951 y por el Protocolo de 1967.

\footnotetext{
${ }^{6}$ Poco después se adoptó el Convenio sobre el genocidio, el 8 de agosto de 1948, y los Convenios de Ginebra sobre Derecho internacional humanitario, el 12 de agosto de 1949.
} 
En un ámbito territorial más restringido, para el caso del continente africano, con una concepción bastante vanguardista, fue adoptada una Convención en el seno de la Organización de la Unión Africana: la Convención de Addis-Abeba, adoptada el 10 de septiembre de 1969, por la que se regulan aspectos específicos de los problemas de los refugiados ${ }^{7}$.

En todo caso, merece la pena subrayar que los refugiados son personas que tienen la ventaja de poder estar cubiertas por normas de Derecho internacional específicas existentes. Estos convenios contienen normas de carácter consuetudinario o convencional, hoy con una aplicación consolidada. En estos casos, la persona que atraviesa una frontera tiene al menos derecho a la aplicación del principio general de non refoulement (no devolución) ${ }^{8}$, lo cual deja al refugiado perseguido en una situación de cierta seguridad jurídica.

\subsection{Los desplazados internos}

Por el contrario, la situación de los desplazados internos es particularmente cruel por dos motivos fundamentales. De un lado, porque los desplazados internos son colectivos particularmente vulnerables, entre los que se cuentan niños no acompañados, mujeres embarazadas, solas o cabeza de familia, grupos étnicos minoritarios, población indígena, enfermos, discapacitados y ancianos. De otro lado, porque el hecho de que permanezcan en el país del que son nacionales, los ubica en una situación jurídica no protegida por el Derecho internacional y seriamente comprometida.

El desplazamiento interno provoca rupturas familiares, corta lazos sociales, expone a personas inocentes a actos de violencia en forma de ataques a los campamentos, desapariciones, violaciones, trabajos forzosos, reclutamiento de niños soldado, etc. Los desplazados internos pueden vivir en campamentos, o fuera de ellos, para huir a fin de ponerse a salvo de posibles fuentes de persecución y de violencia, cuando no acaban por sumergirse en comunidades pobres y desposeídas. Además de verse afectados por las consecuencias de los flujos migratorios, los desplazados internos están expuestos

\footnotetext{
7 Este Convenio entró en vigor en 1974, conforme a lo dispuesto en su art. 2. El artículo titulado «Asilo» determina que «ninguna persona será sometida por un Estado miembro a medidas tales como la negativa de admisión en frontera, la devolución o expulsión que la obligarían a regresar o a permanecer en un territorio donde su vida, su integridad corporal o su libertad estarían amenazadas por las razones enumeradas en los párrs. 1 y 2 del art. 1 ».

8 Tras la Segunda Guerra Mundial, este principio generó un importante consenso en la Comunidad Internacional, ansiosa de hallar una solución para las masas de refugiados y personas desplazadas que vagaban por Europa. Este principio está formulado en el art. 33 de la Convención de 1951. Su redacción ha dado pie a una nutrida discusión doctrinal. Por ejemplo, se ha debatido sobre si su consagración constituyó la cristalización de una norma consuetudinaria o no. Desde el punto de vista convencional, está también recogido en el art. 3 de la Convención contra la tortura y otros tratos o penas crueles, inhumanos o degradantes; el art. 45 del IV Convenio de Ginebra relativo a la protección debida a las personas civiles en tiempo de guerra (Convenio IV); el art. 22 de la Convención Americana de Derechos Humanos; y el art. 2 de la Convención de la OUA por la que se regulan aspectos específicos de problemas de los refugiados en África.
} 
a la muerte y a otro tipo de desgracias. Estas muertes, si bien de un lado, no están provocadas exclusivamente por los conflictos bélicos, de otro lado, llevan a una penosa peregrinación de personas que vagan sin rumbo fijo y que se exponen a la proliferación de enfermedades, de malnutrición o de otro tipo de calamidades. Lo peor de todo es que a veces este colectivo, en la medida que aparece entremezclado en una masa humana heterogénea, es percibido por las comunidades de acogimiento y por los combatientes o por las bandas armadas que operan en la zona en la que se encuentran, como enemigos, como cómplices o como espías de cualquiera de los bandos.

El fenómeno migratorio de los desplazados internos se puede abordar desde distintos puntos de vista. Por ejemplo, atendiendo a la motivación y a los intereses de los Estados de acogimiento de estas personas. Dichos movimientos migratorios pueden ser deseados o no deseados, pero en todo caso son forzados. Particularmente grave es la situación de las personas que se han visto «obligadas» a instalarse en otra zona de su propio país sin traspasar las fronteras internacionales. Para estas personas, en estos supuestos, queda al menos el consuelo de la aplicación del derecho consuetudinario del Derecho internacional de los derechos humanos y del Derecho internacional humanitario vigente al respecto. En todo caso, hay que destacar que la situación de los desplazados internos, a menudo, es análoga a la de los refugiados. Su retorno es complicado ya que, si bien de un lado, su seguridad física puede estar expuesta a las minas antipersona o a otro tipo de peligros, de otro lado, su vuelta a casa presenta dificultades de integración con comunidades ya asentadas que les disputan sus posesiones, sus propiedades o su forma de vida (agricultores, ganaderos, pescadores, etc.).

Hoy en día, según el Observatorio sobre las situaciones de Desplazamiento Interno (IDMC, correspondiente en inglés al Internal Displacement Monitoring Centre $)^{9}$, todo este escenario es significativo porque el número de desplazados internos cuadruplica el número de los refugiados y su número no deja de crecer. Así, en relación con el África subsahariana, a finales de 2013, había 12,5 millones de desplazados internos en 21 países, siendo la región con mayor número de desplazados internos del mundo. En la actualidad, el 63 por 100 de los desplazados internos del planeta se concentra en cinco países: Colombia, Nigeria, República Democrática del Congo, Sudán y Siria. Concretamente, en la República Democrática del Congo, la población desplazada se ha mantenido al mismo nivel que en años precedentes: cerca de tres millones de personas.

Uno de los mayores problemas de los desplazados internos es que ser desplazado interno no constituye una categoría legal autónoma. Los Principios Rectores, y el Convenio de Kampala — de los que hablaremos más adelante-,

9 El Observatorio sobre las situaciones de Desplazamiento Interno fue establecido por el Consejo Noruego para los Refugiados en 1998, a solicitud de la ONU, para que se creara una base de datos global sobre los desplazados internos. Pasados algunos años, este organismo sigue siendo la principal fuente de información y análisis de la situación de los desplazamientos internos debido a conflictos y la violencia en el mundo entero. Véase http://www.internal-displacement.org/. 
ofrecen una identificación descriptiva muy parecida a la de los refugiados, pero todavía no definida completamente. En ambos textos, no se confiere una condición legal especial para los desplazados internos diferentes de los demás nacionales del Estado en cuestión. El párr. 1 de los Principios Rectores ${ }^{10}$ y mutatis mutandi el apartado k) del art. 1 de la Convención de Kampala los describe de la forma siguiente:

«Los desplazados internos son personas o grupos de personas que se han visto forzadas u obligadas a escapar o huir de su hogar o de su lugar de residencia habitual, en particular como resultado o para evitar los efectos de un conflicto armado, de situaciones de violencia generalizada, de violaciones de los derechos humanos o de catástrofes naturales o provocadas por el ser humano, y que no han cruzado una frontera estatal internacionalmente reconocida».

Cuando la situación de los desplazados internos es «forzada» en razón de motivaciones políticas o de situaciones de otra naturaleza, como las catástrofes naturales, los conflictos bélicos, la violación sistemática o masiva del Derecho internacional de los derechos humanos o la vulneración del Derecho internacional humanitario, el desplazamiento interno tiene especial interés debido a razones de diverso tipo: al intento de una categorización jurídica ${ }^{11}$, a la existencia de un estatuto jurídico de los desplazados internos no del todo determinado $^{12}$ o a la identificación de las normas internacionales aplicables en cada situación. De hecho, hasta la adopción de los Principios Rectores — de los que hablaremos más tarde-, existían grandes vacíos y lagunas jurídicas en cada situación en relación con este colectivo tan numeroso.

A diferencia de los refugiados, al no haber abandonado el país del que son nacionales, los desplazados internos siguen siendo titulares de los mismos derechos que disfrutan las demás personas de su país, sin tener en cuenta que estos seres humanos tienen necesidades especiales. Los desplazados internos, al permanecer en el territorio del que son nacionales, se hallan expuestos a mayores peligros. Algunos han abandonado su hogar o incluso la tierra en la que estaban enraizados. Otros desplazados internos son desposeídos de su medio de vida (tierras, ganado, pesca, etc.). Muchos desplazados internos prueban suerte y se ven obligados a trasladarse a lugares aislados, poco seguros o incluso inhóspitos. No es raro encontrar también que ciertos desplazados internos sean testigos o víctimas de violencia como el asesinato, la violación, el reclutamiento forzado a grupos armados o padezcan el trabajo forzado, casi en régimen de esclavitud. Con frecuencia, los desplazados internos pueden encontrarse separados de su familia o temer por la seguridad de los miembros de ésta. Otros desplazados internos se ven obligados a huir sin la documentación que acredite su estado civil o su nacimiento, lo que puede

\footnotetext{
10 E/CN.4/1998/53/Add.2, adición, párr. 2, p. 5.

11 Sobre este particular, véase especialmente CIRERA ForTEA, M. T., Los desplazados internos: un problema internacional. Hacia un estatuto jurídico de los desplazados internos, Barcelona, Asociación para las Naciones Unidas, 2006.

12 En cada país, los desplazados internos tienen unas características diferentes y, en otros, ni siquiera existen. No hay todavía un estatuto jurídico estandarizado.
} 
dificultar su acceso a los servicios sociales más básicos como la educación, la alimentación, el cobijo o alojamiento básico, el vestido adecuado, los servicios médicos o de saneamiento indispensables o también la libre circulación por el país del que son nacionales. En ocasiones, la situación se agrava con el tiempo porque se perpetúa sine die. Por este motivo, se dificulta la reconstrucción de las vidas de los desplazados internos. En definitiva, los desplazados internos son lo contrario a los extranjeros: intervienen en una situación de ausencia de fronteras, pero padecen la desprotección de su propia nacionalidad.

\section{LOS DESPLAZADOS INTERNOS EN EL DERECHO INTERNACIONAL}

Al comienzo de la década de los años noventa, el incremento de conflictos internos y la consiguiente proliferación de desplazados internos condujo a la Organización de las Naciones Unidas a examinar con detenimiento esta situación, si bien el fenómeno no era completamente nuevo. La Comunidad Internacional mostró una honda preocupación por estas personas y se pensó en la necesidad de tomar medidas jurídicas de solución al problema. En concreto, la Comunidad Internacional prestó especial atención al diferente trato, asistencia y protección que deberían percibir los desplazados internos frente a los refugiados que cruzan las fronteras. De hecho, con frecuencia - como ya hemos señalado-, la situación de los desplazados internos es análoga a la de los refugiados.

La situación determinó que en 1992, el secretario general de la ONU, presentara un informe a la Comisión de Derechos Humanos ${ }^{13}$ por la que se nombró un representante sobre la cuestión de los desplazados internos, el sudanés Francis M. Deng ${ }^{14}$. A este representante se le confió inicialmente un mandato por un año para analizar las causas y las consecuencias de los desplazamientos internos, el estatuto de las personas internamente desplazadas en Derecho internacional, el grado de protección que les conceden las normas internacionales existentes, así como la forma de mejorar su protección y asistencia ${ }^{15}$. Desde que la ONU focalizara por primera vez su atención por las crisis de los desplazados internos, muchas Organizaciones Internacionales, organismos internacionales y Organizaciones No Gubernamentales apoyaron una ampliación de aquel mandato hasta $2004^{16}$, así como el alcance de

13 Resolución 1992/73, de 5 de marzo, de la Comisión de Derechos Humanos.

14 A lo largo de estos años han sido designados sucesivamente como representantes del secretario general en materia de los desplazamientos internos varios expertos: primero, Francis M. Deng (19922004), segundo, Walter Kälin, profesor de la Universidad de Berna (2004-2010) y, tercero y último hasta ahora, Chaloka Beyani (desde 2010 hasta hoy).

15 Véanse las Resoluciones 50/195, de 22 de diciembre de 1995, y 1996/52, de 19 de abril de 1996, adoptadas por la Comisión de Derechos Humanos y por la Asamblea General, respectivamente.

16 Doc. N.U./48/, de 9 de noviembre de 1993, p. 1.

En cumplimiento de la Resolución 2004/55 de la Comisión de Derechos Humanos, el secretario general nombró a Walter Kälin como representante del secretario general para los derechos de las personas internamente desplazadas. 
sus actividades para hacer frente con mayor eficacia a los problemas de los desplazamientos internos ${ }^{17}$.

Paulatinamente, los Gobiernos se han hecho más receptivos a la hora de reconocer su responsabilidad primaria de proteger y de asistir a sus nacionales, desvinculándose del sacrosanto principio de no intromisión en los asuntos internos, ante su obligación de cumplir y velar por la existencia del Derecho internacional de los derechos humanos, en tanto obligación erga omnes. En virtud de esta obligación, quiere entenderse que todo Estado tiene un interés legítimo en la protección de las personas que se encuentran en su territorio cualquiera que sea su nacionalidad. La soberanía es concebida como responsabilidad del bienestar de esta población por lo que resulta legítimo que, desde el sistema de Naciones Unidas, se hayan ido preparando instrumentos para verificar el cumplimiento de las obligaciones que comporta el trato a las personas que se encuentran bajo su jurisdicción y se hayan propuesto fórmulas para mejorar el desempeño por las autoridades estatales de esta tarea. Ello determina que, cuando las autoridades nacionales no pueden hacer frente por falta de medios al fenómeno migratorios de los desplazados internos, progresivamente las autoridades de acogimiento se han ido mostrando cada vez menos reacias a solicitar asistencia a la Comunidad Internacional, desvinculándose en tal supuesto de su firme adhesión a la doctrina de la soberanía nacional. No fue hasta ese momento cuando entran en acción los organismos o las agencias internacionales humanitarias con el fin de prestar ayuda, asistencia y protección a los desplazados internos y a los refugiados. Sin embargo, es lamentable constatar que la normativa y las instituciones con las que podría contar la Comunidad Internacional al respecto eran todavía deficientes, aunque hubiera estado animada por buenos propósitos en su pretensión de responder con plena eficacia al problema.

En 1996, el segundo paso fue la compilación y el análisis de las normas jurídicas aplicables a los desplazados internos. Esta compilación de normas internacionales se presentó a la Comisión de Derechos Humanos en $1996^{18}$. Hecho público este texto, cincuenta expertos independientes pusieron sobre la mesa los Principios Rectores en un congreso que contó con la colaboración de Organizaciones regionales e internacionales, Organizaciones No Gubernamentales humanitarias y de derechos humanos, grupos de defensa de la mujer y de la infancia. Este congreso se celebró en Viena; lo presidió el Gobierno austríaco, uno de los principales patrocinadores del documento. La Comisión de Derechos Humanos aprobó, en abril de 1997, la Resolución 1997/39 ${ }^{19}$ en la que tomaba nota de la preparación de los Principios Rectores. Los trabajos concluyeron un año después. En 1998, el representante sobre las cuestiones de los desplazados internos, el citado Francis M. Deng, presentó su informe

\footnotetext{
17 Doc. N.U.E/CN.4/2005/84.

18 E/CN.4/1996/52/Add. 2.

19 E/CN.4/1998/52/Add. 2.
} 
ante la ONU. Este informe contiene como adición el listado de treinta Principios Rectores de los desplazados internos ${ }^{20}$.

Al poco tiempo, algunos Gobiernos liderados por Egipto, Sudán y la India se hicieron oír. Estos Estados empezaron a cuestionar la condición de los Principios Rectores y a plantear si su desarrollo por actores no gubernamentales supondría o no un precedente preocupante. Para aplacar sus temores, el Gobierno suizo presidió varios encuentros que se iniciaron en 2001. A su término, los Gobiernos discrepantes acabaron por abandonar sus reservas y expresaron su apoyo a los Principios Rectores. En concreto, se recordó a los grupos de redactores que el documento en gran parte compilaba y reformulaba temas ya negociados y acordados por los Gobiernos. También se dejó influir por numerosos Gobiernos el Grupo de los 77, un grupo de países que también acabó por descubrir en este documento una valiosa herramienta para afrontar el desplazamiento interno en sus respectivos territorios. El Proyecto BROOKINGS sobre el Desplazamiento Interno ${ }^{21}$ colaboró muy activamente con Organizaciones Internacionales, regionales y con la sociedad civil organizada de todo el mundo para recabar el reconocimiento internacional de los Principios.

De forma deliberada, la redacción de este texto se atribuyó no a los Estados - lo que es habitual-, sino a un grupo de expertos jurídicos internacionales ${ }^{22}$, que trabajaron en colaboración con agencias internacionales y Organizaciones No Gubernamentales. Un punto controvertido fue decidir qué forma jurídica se iba a dar a las reglas aplicables a los desplazamientos internos, si se les daba forma de declaración o si se les daba forma de tratado internacional ${ }^{23}$. Al final, se adoptaron unas normas de soft law aplicables universalmente ya que éstas reafirman normas consuetudinarias, el Derecho internacional de los derechos humanos y el Derecho internacional humanitario vigente en la materia. El equipo de expertos identificó áreas significativas en las cuales el Derecho existente falla a la hora de proporcionar una base adecuada para la protección y asistencia a los desplazados internos. Los Principios Rectores han sido recogidos en una resolución de la Comisión de Derechos Humanos ${ }^{24}$ de manera que recalcan la autoridad moral que están

20 E/CN.4/1998/53/Add. 2, adición que contiene los Principios Rectores. La base jurídica de cada PR se estableció en las anotaciones a los Principios Rectores escritos por Walter Kälin. Véase KäLIN, W., "Guiding Principles on International Displacement: Annotations», Studies in Transnational Legal Policy, 2. ${ }^{a}$ ed., 38, 2008 (The American Society of International Law y el Proyecto BROOKINGS-Berna sobre los desplazados internos. Disponible en http://www.asil.org/pdfs/stlp.pdf).

21 http://www.brookings.edu/projects/idp.aspx.

22 Fue la primera vez que un grupo de expertos ejercía esta labor, en detrimento de los Gobiernos.

23 Otro punto de discusión fue determinar la forma más conveniente para compilar las reglas relativas a la protección y la asistencia de los desplazados internos. Mientras que los juristas norteamericanos defendían un planteamiento basado en empezar por la identificación de los derechos y garantías de los desplazados internos, para luego discutir su forma jurídica; los europeos presentaron un planteamiento más conservador. Los europeos proponían estudiar exclusivamente las normas de hard law en la materia. La decisión sobre la identificación de los derechos recayó en Walter Kälin, que supo conciliar ambas perspectivas. El informe resultante fue presentado en dos partes por Francis M. Deng ante la Comisión de Derechos Humanos en 1996 y en 1998.

${ }^{24}$ Los Principios Rectores fueron presentados a la Comisión de Derechos Humanos en su $54 .^{\circ}$ periodo de sesiones de 1998. Véase (E/CN.4/1998/53/Add. 2) como una adición a su informe anual. 
infundiendo entre los Estados, las Organizaciones No Gubernamentales y los organismos que prestan ayuda humanitaria.

Estos Principios Rectores son relevantes para el trabajo de las autoridades nacionales, de los agentes no gubernamentales, de las agencias internacionales y de las Organizaciones No Gubernamentales (párr. 3 de los Principios Rectores) ${ }^{25}$. Los Principios Rectores enuncian especialmente derechos y proporcionan cierta seguridad jurídica para los desplazados internos. En concreto, los Principios Rectores confieren a éstos el derecho a morar con seguridad y dignidad durante el desplazamiento y les atribuye también el derecho al retorno o la posibilidad de un reasentamiento sin peligro, así como su reintegración en otro lugar diferente de su vivienda habitual (apdo. 1 de los Principios Rectores) ${ }^{26}$.

Para concederles más autoridad, con los Principios Rectores, se procedió del siguiente modo. Estos Principios Rectores no contradicen en modo alguno la normativa internacional de derechos humanos, ni el Derecho internacional humanitario, ni el de carácter consuetudinario (apdo. 3 de los Principios Rectores). Contrariamente a ello, los Principios Rectores se sirven y se apoyan en la normativa existente. Los Principios Rectores operan a modo de recopilación, síntesis y sistematización de aquellas normas que se encuentran dispersas en una amplia variedad de textos internacionales, tienen carácter consuetudinario, o son principios generales de Derecho internacional; de ahí que haya resultado complicada la labor de identificación, ya que se trata de derechos difusos y periféricos a la hora de conceder protección y asistencia a los desplazados internos. En consecuencia, los Principios Rectores reafirman el valor de las normas aplicables, aclaran ambigüedades y, tratan de colmar lagunas. Dichas disposiciones se aplican durante todas las fases del desplazamiento ${ }^{27}$.

En nuestra opinión, los Principios Rectores son altamente positivos ya que pretenden ser una declaración de carácter persuasivo y preventivo que aportan una orientación práctica a los operadores en su trabajo y una claridad jurídica que anteriormente se veía enturbiada por el carácter disperso de las normas aplicables. Al mismo tiempo, estas disposiciones educan y se proponen concienciar sobre la problemática de los desplazados internos en particular. Los Principios Rectores tratan de prevenir, que no curar, respecto de los desplazamientos arbitrarios (apdo. 1 del Principio Rector 5) ${ }^{28}$. Para ello, los desplazados internos retienen una amplia gama de derechos económicos, sociales culturales, cívicos y políticos, incluyendo el derecho a la asistencia humanitaria básica.

25 E/CN.4/1998/53/Add. 2, p. 5.

26 Ibid., p. 5.

27 La adición de los Principios Rectores está estructurada en secciones. Tras indicar los aspectos generales de los Principios Rectores en la sección primera; en la sección segunda, se enumeran los Principios básicos de todo desplazado; la sección tercera enuncia los Principios relativos a la protección durante el desplazamiento; la sección cuarta contiene los Principios relativos al regreso, el reasentamiento y la reintegración de los desplazados internos.

28 E/CN.4/1998/53/Add. 2, p. 5. 
Los Principios Rectores, igual tratan el tema del alimento, como lo hacen sobre los medicamentos, el alojamiento, el agua y su abastecimiento o, el derecho a estar protegido frente a la violencia física. Se trata de evitar, en la medida de lo posible, que los desplazados internos se vean obligados a optar por dejar su hogar contra su voluntad o incluso a abandonar su país de origen. A tenor de la aplicación del art. 13 de la Declaración Universal de los Derechos Humanos, se prohíbe de forma absoluta la aplicación de la limpieza étnica, el apartheid y los desplazamientos utilizados como castigo colectivo [apdo. 2.a) del Principio Rector 6 ${ }^{29}$. La protección existente en tiempo de guerra supone la prohibición del desplazamiento a menos que se pueda demostrar la necesidad de ofrecer seguridad a la población afectada por razones militares o de seguridad [apdo. 2.c) del Principio Rector 10]. También se insiste en el hecho de que la aplicación de los Principios Rectores no afecta a la responsabilidad penal del individuo con arreglo al Derecho internacional, en particular en relación con el delito de genocidio, los crímenes de lesa humanidad y los crímenes de guerra (párr. 2 del Principio Rector 1).

El desplazamiento se concibe como excepción; por ello, la carga de la prueba corresponde a las partes en conflicto (según prevé el art. 17 del Protocolo II de Ginebra de 1949 y reafirma el Principio Rector 12). Durante un conflicto, trasladar a las personas puede ser la mejor forma y más humanitaria para salvaguardar su integridad física, pero es el último recurso. Se especifica también para proteger a los desplazados internos que es importante recabar la opinión de éstos sobre su destino. Este hecho supone que hay que consultar con ellos e identificar alternativas posibles (apdo. 2 del Principio Rector 28).

Durante el desplazamiento, para minimizar su alcance, los Principios Rectores establecen que: no se pueden violar los derechos de los desplazados internos a la vida (Principio Rector 12); a la dignidad y a la integridad física, mental o moral (Principio Rector 11); a la libertad y la seguridad personal (Principio Rector 12); al derecho a la libertad y seguridad personales (Principio Rector 12); al derecho a la libertad de circulación y a la libertad de escoger su residencia (Principio Rector 13); al derecho a conocer el destino y paradero de sus familiares desaparecidos (Principio Rector 16); al derecho a su vida familiar (Principio Rector 17); al derecho a un nivel de vida adecuado (Principio Rector 18); al derecho a su propia personalidad jurídica (Principio Rector 21); al derecho a propiedad o a sus posesiones (Principio Rector 23), y al derecho a la educación (Principio Rector 23). Las autoridades deben brindar y ofrecer alojamientos adecuados y no separar a las familias.

Resumiendo, cuatro son los Principios Rectores básicos: 1. La igualdad de los derechos e igualdad de obligaciones que el resto de los nacionales del país (apdo. 1 del Principio Rector 1); 2. Su aplicación universal (apdo. 1 del enunciado titulado «Principios Rectores de los desplazados internos: introducción: alcance y finalidad» y apdo. 1 del Principio Rector 2) y sin discrimi-

29 E/CN.4/1998/53/Add. 2, p. 6. En relación con las siguientes reglas existentes en los Principios Rectores véanse las pp. 8, 5, $914,9,10,11,5,6$ y 13, respectivamente. 
nación (apdo. 1 in fine del Principio Rector 1), de tal forma que los Principios Rectores son aplicables universalmente en la medida en que reafirman normas de Derecho internacional ya existente; 3 . Derecho a la búsqueda y disfrute de asilo en otros países (apdo. 2 del Principio Rector 2), y 4. Soberanía entendida como responsabilidad (apdo. 1 del Principio Rector 3, y Principio Rector 25), de la que hablaremos más adelante.

Transcurridos tres lustros desde su publicación en un informe de 1998 al ECOSOC, el secretario general de la ONU calificó los Principios Rectores como «uno de los logros más importantes en el área humanitaria». Desde entonces, los jefes de Estado y de Gobierno, reunidos en la Cumbre mundial de 2005 han recogido los Principios Rectores como «un marco internacional de importancia para proteger a las personas desplazadas dentro de los países ${ }^{30}$. El secretario general de la ONU apuntó su preocupación por la suerte de los desplazados internos al afirmar que «[...] gran parte de África, sobre todo al Sur del Sáhara, sigue sufriendo los trágicos efectos de conflictos violentos y persistentes, la extrema pobreza y las enfermedades. Unos 2,8 millones de refugiados, y la mitad de los 24,6 millones de personas internamente desplazadas que hay en el mundo, son víctimas de los conflictos y los trastornos de África. África sigue yendo a la zaga del resto de países en desarrollo en el logro de los objetivos del Milenio ${ }^{31}$.

Los Principios Rectores se han convertido en referencia clave para el desarrollo del marco normativo de protección de los desplazados internos que recogen la legislación y las políticas nacionales. Tal es el caso de ciertos países como Angola, Burundi, Sierra Leona, Liberia, Uganda y Sudán. Otros países están aún en proceso de desarrollar su normativa nacional en materia de protección y asistencia a los desplazados internos.

Sin embargo, no existe un organismo específico que se ocupe exclusivamente de proteger y ayudar a los desplazados internos. Los organismos que se mencionan a continuación tienen la responsabilidad de coordinar la respuesta en situaciones especiales. En caso de emergencia, el Alto Comisionado para los Derechos Humanos actúa como líder de grupo en materia de protección, alojamiento de emergencia y en gestión y coordinación de los campos; el Programa de Naciones Unidas para el Desarrollo interviene para la recuperación temprana. En casos de desastre natural, la coordinación internacional se atribuye a la Organización Internacional de Migraciones, y el alojamiento de emergencia es competencia de la Federación Internacional de la Cruz Roja. La responsabilidad de brindar protección en zonas de desastre o en otras situaciones que requieren respuesta de protección, se decide con la consulta a dos organismos de Naciones Unidas (Alto Comisionado para los Derechos Humanos y UNICEF) según cada caso.

30 Véase la Resolución 60/1, de 24 de octubre de 2005, titulada «Documento final de la Cumbre de 2005», A7RES/60/1.

31 Véase el informe del secretario general, de 21 de marzo de 2005, titulado «Un concepto amplio de libertad: desarrollo, seguridad y derechos humanos para todos», A/59/2005, p. 26. 


\section{LA RESPONSABILIDAD DE PROTEGER APLICADA A LOS DESPLAZAMIENTOS INTERNOS}

Al final de la década de los noventa del siglo xx, se produjo simultáneamente una nueva percepción del concepto básico del Derecho internacional: el de la soberanía. Este concepto, al combinarlo con la situación de los desplazados internos, empezó a presentar unas características singulares. A raíz de la propuesta presentada en 2001 por la Comisión Internacional sobre la Intervención y Soberanía Estatal (ICISS) ${ }^{32}$, se insistió en que la finalidad de la soberanía no sólo sirve para generar derechos a los Estados ${ }^{33}$, sino que ésta se puede proyectar desde la perspectiva de la responsabilidad del Estado soberano. Se dio forma a la idea de que, por el hecho de ser soberanos, los Estados no gozan de extensos derechos - casi ilimitados- ni sobre los extranjeros que se encuentren en su territorio, ni sobre sus propios nacionales a los que deben proteger y amparar como desde hace tiempo determina el Derecho internacional general. A todas estas personas, el Estado debe asegurar la protección y la asistencia ante la vigencia del Derecho internacional de los derechos humanos en tiempos de paz, y del Derecho internacional humanitario en aquellos casos en que éste esté vigente.

En esta nueva visión del Derecho internacional, la soberanía, sin perder su naturaleza nuclear para este ordenamiento jurídico internacional e interno, se encuentra erosionada y matizada por el desarrollo que ha tenido la Carta de Naciones Unidas que se ha reconocido a la Declaración Universal de los Derechos Humanos y de otros tantos tratados en materia de derechos humanos. Se trata de una renuncia de la Comunidad Internacional a inmiscuirse en los asuntos internos con el objetivo de verificar la existencia de causas generadoras de éxodos masivos forzados.

El problema se plantea cuando un Estado o no puede o no quiere asumir esta responsabilidad. En tal caso, dicha responsabilidad corresponde a la Co-

\footnotetext{
32 Véase http://responsibilitytoprotect.org/ICISS\%20Report.pdf. Sobre el particular, a mayor abundamiento, véanse entre otros en la doctrina española BERMEJO GARcía, R., «El genocidio en Ruanda diez años después: una vergüenza para la comunidad internacional a la luz del principio de la responsabilidad de proteger», en CAFlish, R., Bermejo García, R., Díez-Hochleitner RodríGuez, C. y GutiérRez EsPADA, C., El Derecho internacional: normas, hechos y valores: liber amicorum José Antonio Pastor Ridruejo, Madrid, Universidad Complutense (Facultad de Derecho), 2005, pp. 265-286, y CERvell HorTAL, M. J., Naciones Unidas, Derecho internacional y Darfur, Granada, Comares (colección «Ciencia jurídica y Derecho internacional», núm. 21), 2010; Cervell Hortal, M. J. y Gutiérrez EsPada, C., Nacimiento, auge y decadencia del principio de la responsabilidad de proteger, Granada, Comares, 2014, etcétera.

33 Esta perspectiva conservadora fue formulada por la CPJI, en 1928, en el bien conocido asunto Isla de Palmas cuando señaló que «la soberanía en las relaciones internacionales significa independencia. La independencia en relación con una parte del globo es el derecho a ejercer en ésta las funciones estatales, con exclusión de cualquier otro Estado». Bien es sabido que esta perspectiva ha sido en gran parte superada. Se ha ampliado el concepto de la soberanía estatal ante la constatación de la existencia de otros sujetos de Derecho internacional como las Organizaciones Internacionales y de la existencia de otros límites nacidos en el marco del Derecho internacional determinado. Esta situación cabe combinarla con la existencia de la intangibilidad del principio de intervención en los asuntos internos de los Estados. Aun así, no es raro encontrar Estados que se aferren todavía a esta percepción de la soberanía tan restrictiva. Fue una percepción que dominó especialmente el periodo de la Guerra Fría.
} 
munidad Internacional. Esta idea está recogida de forma explícita en dos Principios Rectores: de forma general, en el Principio Rector $3^{34} \mathrm{y}$, de forma específica — referida a la prestación de ayuda humanitaria—, en el Principio Rector 25.

«Principio Rector 3. 1. Las autoridades nacionales tienen la obligación y la responsabilidad primarias de proporcionar protección y asistencia humanitaria a los desplazados internos que se encuentren en el ámbito de su jurisdicción.

2. Los desplazados internos tienen derecho a solicitar y recibir protección y asistencia de estas autoridades. No serán perseguidos ni castigados por formular esa solicitud».

«Principio Rector 25. 1. La obligación y responsabilidad primarias de proporcionar asistencia humanitaria a los desplazados internos corresponde a las autoridades nacionales.

2. Las organizaciones humanitarias internacionales y otros partícipes competentes tienen derecho a ofrecer sus servicios en apoyo de los desplazados internos. Este ofrecimiento no podrá ser considerado como acto inamistoso ni como injerencia en los asuntos internos del Estado y será examinado de buena fe. Su aceptación no podrá ser retirada arbitrariamente, en particular cuando las autoridades competentes no puedan o no quieran proporcionar la asistencia humanitaria.

3. Todas las autoridades competentes concederán y facilitarán el paso libre de la asistencia humanitaria y permitirán a las personas que prestan esa asistencia un acceso rápido y sin obstáculos a los desplazados internos».

Desde que fueron adoptados los Principios Rectores sobre los desplazados internos en 1998, éstos se han convertido en normas internacionales aceptadas en el ámbito del desplazamiento interno. Además, cada vez más son los propios Estados los que incorporan en su legislación interna estos Principios (por ejemplo, Colombia o Uganda). De esta forma, los Principios Rectores han pasado a convertirse en parámetro de referencia utilizado por los actores humanitarios y los activistas de los derechos humanos que se ocupan de estos asuntos. Se está consiguiendo incluso que los propios desplazados internos empiecen a tomar conciencia de sus propios derechos. Con todo, siguen existiendo países afectados por los desplazamientos internos que no han adoptado legislación interna al respecto y en ellos, las personas que padecen esta situación no son conscientes de sus derechos (por ejemplo, en la República Democrática del Congo, en Sudán o en Afganistán). Desde las instancias internacionales — sobre todo desde la ONU— se han hecho reiterados llamamientos para que los Gobiernos compartan sus experiencias y asuman sus responsabilidades.

34 E/CN.4/1998/53/Add. 2, pp. 6 y 13, respectivamente. 


\section{LA LABOR DE LA CONFERENCIA INTERNACIONAL DE LA REGIÓN DE LOS GRANDES LAGOS REFERIDA A LOS DESPLAZADOS INTERNOS}

La Conferencia Internacional de la Región de los Grandes Lagos ${ }^{35}$ fue creada en el año 2006 a instancias de la Secretaría General de la ONU y de la UA. La conferencia diplomática que la puso en marcha se celebró en Nairobi (Kenia). La CIRGL nació con el propósito de poner fin a los conflictos ocurridos en la Región de los Grandes Lagos al final de la década de los noventa. Aunque el punto de inflexión se alcanzó con el genocidio en Ruanda de 1994, este área geográfica también experimentó el azote particularmente severo y sangriento de toda una serie de conflictos — como la llamada «Primera Guerra Mundial de África» de $1998^{36}$ - que involucró a siete países limítrofes de los Grandes Lagos ${ }^{37}$. El resultado de todos estos conflictos se tradujo en un desastre humanitario de grandes proporciones, que determinó una tremenda inestabilidad política, económica y social de toda la región, en condiciones de amenazar la paz y la seguridad en la zona ${ }^{38}$. La celebración de la CIRGL reconocía la dimensión regional de los conflictos, al tiempo que ponía de manifiesto la necesidad de un esfuerzo concertado con vistas a lograr la paz. Los Estados miembros de la CIRGL eran y son: Angola, Burundi, la República Centroafricana, la República del Congo, la República Democrática del Congo, Kenia, Uganda, Ruanda, Sudan, Tanzania, Zambia y Sudan del Sur.

En el año 2000, el Consejo de Seguridad de la ONU en sus Resoluciones $1291^{39}$ y $1304^{40}$ animó y promovió la organización de una conferencia internacional sobre la paz, la democracia y el desarrollo en la Región de los Grandes Lagos. El 20 de noviembre de 2004, los esfuerzos se concretaron con la adopción por parte de los jefes de Estado de la Declaración sobre la

35 Véase http://www.icglr.org/.

36 Véase, por ejemplo, Vacas Fernández, F. y Pardo de Santayana, J., El conflicto de los Grandes Lagos, Madrid, Ministerio de Defensa (colección «Conflictos internacionales contemporáneos», núm. 1), 2005, 143 pp., y Cervera Vallterra, M., «El caso de la República Democrática del Congo: efectos perversos de la globalización en un estado fallido", Anuario de Derecho Internacional, 2014, pp. 87-138; Chandra Lekha, S., Martín-Ortega, O. y Herman, J., "Democratic Republic of Congo», War, conflict and human rights: theory and practice, 2. ${ }^{\mathrm{a}}$ ed., Londres y Nueva York, Routlege, 2014.

37 Si de un lado estaban Burundi, Ruanda y Uganda; en apoyo de la República Democrática del Congo acudieron tropas de Zimbabue, Angola, Namibia, Chad y Sudán. Este conflicto internacional se prolongó oficialmente entre agosto de 1998 y junio de 2003, y de él todavía subsiste la acción armada contra la población civil.

38 Resolución 1254, de 9 de abril de 1999, S/RES/1234.

39 Resolución 1291, de 24 de febrero de 2000, S/RES/1291 (2000). Con esta resolución, habiendo sido creada con anterioridad — mediante la Resolución 1254- la Operación de Naciones Unidas en la República Democrática del Congo (MONUC, 1999-2010), se atribuyó el uso de la fuerza a dicha misión sobre la base del capítulo VII de la Carta siempre que fuera en defensa de la propia misión. Con esta Resolución, el Consejo de Seguridad transformó el mandato inicial de MONUC para favorecer el desarme voluntario de los grupos armados de la República Democrática del Congo en un mandato enmarcado en el capítulo VII de la Carta de Naciones Unidas. Los efectivos de las Naciones Unidas se ampliaron a 5.537 efectivos. A esta misión, le ha seguido otra misión de Naciones Unidas: la Misión de Estabilidad en la República Democrática del Congo (MONUSCO) iniciada en 2010 y que hoy sigue operativa.

40 Resolución 1304, de 16 de junio de 2000, S/RES/1304. 
paz, la seguridad y el desarrollo en la Región de los Grandes Lagos en Dar es-Salaam (Tanzania). Esta declaración recogía la voluntad política de atajar las causas profundas de los conflictos y los obstáculos para el desarrollo con una perspectiva regional innovadora. Dos años después de la adopción de esta Declaración, los jefes de Estado y de Gobierno se congregaron de nuevo en Nairobi para firmar entre el 14 y el 15 de diciembre de 2006 el Pacto sobre la seguridad, la estabilidad y el desarrollo en la Región de los Grandes Lagos. Este Pacto tiene una importancia significativa y es la base de la acción de la UA y de la CIRGL en cuanto a la búsqueda de soluciones políticas y jurídicas para la Región de los Grandes Lagos. Consta de varios documentos: la propia Declaración de Dar es-Salaam y, varios Protocolos ${ }^{41}$ y Programas de acción ${ }^{42}$. La adopción de este Pacto acaba la primera fase preparatoria de actuación y abre la nueva puesta en marcha de una Secretaría Ejecutiva de la CIRGL ${ }^{43}$ con sede en Bujumbura (Burundi). La Secretaría se inauguró en mayo de 2007. La CIRGL se basa en una estructura institucional ad hoc que descansa sobre varias instituciones: un mecanismo regional de seguimiento (art. 22 de la Declaración); una cumbre que opera como órgano supremo de la CIRGL, que se reúne cada dos años y toma las decisiones más importantes mayoritariamente por consenso (art. 23 de la Declaración); un órgano ejecutivo, llamado comité interministerial regional, que presenta un informe periódico ante la cumbre cada dos años (art. 24 de la Declaración); un grupo ad hoc de expertos que prepara informes especiales sobre problemas específicos de los

41 Estos protocolos son: un protocolo sobre la no agresión y la defensa mutua en la Región de los Grandes Lagos (art. 5 de la Declaración), un protocolo sobre la democracia y la buena gobernanza (art. 6 de la Declaración), un protocolo sobre la cooperación judicial (art. 7 de la Declaración), un protocolo sobre la prevención y la represión del crimen del genocidio, los crímenes de guerra y los crímenes de lesa humanidad y de todas las formas de discriminación (art. 8 de la Declaración), un protocolo sobre la lucha contra la explotación ilegal de los recursos naturales (art. 9 de la Declaración), un protocolo sobre la zona específica de reconstrucción y desarrollo (art. 10), un protocolo sobre la prevención y la represión de la violencia sexual contra las mujeres y niños (art. 11 de la Declaración), un protocolo sobre la protección y asistencia de las personas desplazadas (art. 12 de la Declaración), un protocolo sobre los derechos de la propiedad de los repatriados (art. 13 de la Declaración), un protocolo sobre la gestión de la información y de la comunicación (art. 14). Se da a entender, en el art. 15, que los Estados acuerdan que otros protocolos adoptados con posterioridad también formarán parte del Pacto y entrarán en vigor según las reglas establecidas en el art. 33.

42 Los programas de acción son cuatro: un programa de acción por la paz y la seguridad (art. 27 de la Declaración), un programa de acción para la democracia y la buena gobernanza (art. 18 de la Declaración), un programa de acción por el desarrollo económico y la integración regional (art. 19 de la Declaración) y un programa de acción sobre los temas humanitarios, sociales y medioambientales (art. 20 de la Declaración). Este último es el más interesante a los efectos de los desplazados internos y los refugiados ya que, entre otros, obliga a los Estados de acogimiento a identificar, desarmar, separar y acoger los elementos armados o los obliga a adoptar otras medidas que neutralizarlos, tal y como establece el Derecho internacional humanitario y el Derecho consuetudinario aplicable. En este plan de acción se presta especial atención al problema del retorno y a la reintegración de los refugiados y de los desplazados internos.

43 La Secretaría Ejecutiva de la CIRGL efectúa labores de coordinación, facilita, gestiona y pone en marcha el Pacto para garantizar la puesta en marcha de las condiciones de paz, seguridad, estabilidad política y desarrollo en los Grandes Lagos. Su programa principal versa sobre los siguientes aspectos: paz y seguridad; democracia y buena gobernanza; desarrollo económico e integración regional; y temas humanitarios y sociales. En el marco de este programa se adoptan temas transversales vinculados al género, al medio ambiente, a los derechos humanos y al SIDA. 
Estados miembros y un fondo especial para la reconstrucción y el desarrollo en colaboración con el Banco Africano de Desarrollo (art. 21 de la Declaración).

De todos los documentos adoptados en el seno de la CIRGL, cabe resaltar a los efectos de los desplazados internos, dos Protocolos: el Protocolo sobre la protección y asistencia de las personas desplazadas en el interior del país del que son nacionales y el Protocolo sobre la propiedad de los repatriados. Con estos dos textos, se pretendió reforzar la asistencia y la protección de los desplazados internos en tanto en cuanto colectivo especialmente vulnerable. El primero de estos Protocolos (art. 12 de la Declaración) tiene la particularidad de hacer suyo y recoger como anexo los Principios Rectores sobre desplazados internos adoptados por Naciones Unidas en 1998, lo que les confiere una fuerza jurídica, si bien no vinculante, marco de referencia jurídica de primer orden. En este protocolo, se subraya la responsabilidad de los Estados sobre el bienestar de sus propios nacionales y les atribuye toda una serie de obligaciones al respecto (art. 3 del Protocolo). Para completar este protocolo, se adoptó otro relativo a los derechos de propiedad de los repatriados (art. 13 de la Declaración), que proporciona garantías jurídicas para los desplazados internos repatriados a fin de que puedan recuperar sus bienes y así asegurarles el retorno a su residencia de origen. En este protocolo, incluso se determinó la creación de un marco jurídico destinado a resolver las controversias que favorezcan la recuperación de sus bienes y propiedades anteriores, y que pertenezcan a los repatriados. Queremos destacar en todo caso que la labor de la CIRGL ha sentado un precedente fundamental y simultáneo en la actuación posterior llevada a cabo por la UA.

\section{PERSPECTIVAS DE FUTURO Y CONSIDERACIONES FINALES: LA CONVENCIÓN DE LA UNIÓN AFRICANA PARA LA PROTECCIÓN Y LA ASISTENCIA DE LOS DESPLAZADOS INTERNOS EN ÁFRICA (CONVENCIÓN DE KAMPALA)}

África es seguramente el ámbito geográfico más convulsionado desde el final de la Guerra Fría por conflictos de tipo colonial o como resultado del intervencionismo de las grandes potencias. Esto explica que la Organización de la Unión Africana - ahora Unión Africana - haya sido de nuevo pionera en relación con los movimientos de personas vulnerables ${ }^{44}$. Como ya ocurriera con los refugiados en 1969, la UA, adelantándose al tiempo, ha aprobado la primera convención vinculante en materia de protección y asistencia a los

44 En 2012, más de un tercio de los 28,8 millones de desplazados internos en todo el mundo vivían en África. Los países más afectados por el desplazamiento interno fueron Sudán, la República Democrática del Congo y Somalia. Ello ha supuesto un incremento del 7,5 por 100 frente al año 2011, que contó con 9,7 millones. En 2012, había 10,4 millones de desplazados internos en 18 países del África subsahariana. 
desplazados internos de ámbito continental, conocida como Convención de Kampala.

En noviembre de 2012, con la ratificación de Suazilandia —el decimoquinto país en depositar este tipo de instrumento normativo-, se alcanzó el número necesario de países para respaldar la validez de dicha convención como parte del Derecho internacional. La Convención de Kampala entró en vigor el 6 de diciembre de 2012. Así, se culminaba un lento proceso de redacción iniciado cuando se adoptaron los Principios Rectores en el ámbito universal en la ONU pero que en África sigue teniendo especial importancia. Este texto internacional se elaboró coincidiendo con la transformación de la OUA en la UA y su aspiración de revisar y mejorar la eficacia de todos los estatutos y los tratados internacionales de la OUA. El trabajo concreto de elaboración del texto se inició en julio de 2004 con la decisión del Consejo Ejecutivo de la UA de establecer un marco jurídico específico para el problema de los desplazados internos ${ }^{45}$. Este comienzo del trabajo de elaboración del tratado en cuestión se produjo casi coincidiendo con la adopción del Pacto sobre la seguridad, la estabilidad y el desarrollo en la Región de los Grandes Lagos.

La redacción de un proyecto jurídico en la UA para los desplazados internos se encomendó a un experto que ya había trabajado en la elaboración del Protocolo sobre los desplazados internos de la CIRGL: el Sr. Chaloka Beyani. Con esta actuación, se trataba de colmar un vacío jurídico sobre los desplazados internos aplicable a todo el continente africano. Se aprovechó especialmente los logros de la CIRGL. El proyecto de tratado fue presentado por el experto a la Comisión Africana en mayo de 2006; sirvió de punto de partida para la redacción de la Convención de Kampala. Entre 2006 y 2008, cada institución de la UA presentó sus contribuciones (la Conferencia interministerial, el Consejo Ejecutivo, los Estados miembros de la UA, un grupo consultivo de expertos y Organizaciones No Gubernamentales). Su adopción final no se produjo hasta el año 2009 con la firma por parte de los jefes de Estado y de Gobierno de la UA. Era la primera vez que un convenio era adoptado en la UA a través de la celebración de una cumbre especial. La elección de Kampala (Uganda) como lugar de la adopción del texto no fue casual: se debía a que era la ciudad de un Estado especialmente golpeado por los conflictos internos.

Al promover e impulsar este texto internacional, la UA ha intentado proponer soluciones a medio y corto plazo que supongan una mejora real y detallada de las condiciones de vida de los desplazados internos, como población civil más vulnerable puesto que, en el continente africano, los flujos masivos de personas constituyen un verdadero problema (art. 2 de la Convención de Kampala). Sin embargo, no es la primera vez que se han puesto sobre la mesa iniciativas sobre la situación de los desplazados internos en el mundo ${ }^{46}$.

45 Doc. U.A. EX.CL/dec. 129 (V) y Doc. UA EX.CL/Dec. 127 (V).

46 Los avances realizados en Colombia son particularmente interesantes ya que incluso se ha llegado a integrar el problema de los desplazados internos en el bloque constitucional. Véase SÁNCHEZ 
En el momento de su adopción, este texto fue acogido como una realización extraordinaria, como un acervo importante y como una herramienta indispensable. Hasta ahora, la Convención de Kampala es el único tratado destinado a proteger a quienes sufren los conflictos armados y sus consecuencias en su dimensión regional. Este texto pone de relieve la multiplicidad, la complejidad y la interdependencia de las causas del desplazamiento interno, ya se deban a conflictos bélicos, catástrofes naturales como inundaciones y tempestades y - por qué no señalarlo-, por la puesta en marcha de proyectos de desarrollo a gran escala como la construcción de una presa, siempre que entrañe desplazamientos internos.

En este texto, se definen las responsabilidades atribuidas a los diferentes actores implicados en la resolución de este problema y, entre ellos, se alude no sólo a los Estados [apdo. d) del art. 2 y arts. 3 a 5 y 9 de la Convención de Kampala] -destinatarios principales-, sino sobre todo a los organismos internacionales, Organizaciones No Gubernamentales (art. 6 de la Convención de Kampala), y lo que es más innovador a los grupos armados [apdo.e) del art. 2 y apdo. 5 del art. 7 de la Convención de Kampala] y a los grupos no estatales [apdo. e) del art. 2 y art. 24 de la Convención de Kampala y apdo. $n$ ) del art. 1 de la Convención de Kampala] para que protejan, cuando no socorran o dejen de atacar a los desplazados internos. Entre estos grupos no estatales se encuentran las compañías multinacionales, las Organizaciones Internacionales y las empresas de seguridad privada [apdo. 1.k) del art. 3]. Consideramos que la Convención de Kampala posee una relevancia nuclear y un hecho sin precedentes. Se presenta como punto de referencia y de apoyo para los Estados miembros que quieran regular este problema con políticas y leyes de ámbito nacional (apdo. 2 del art. 3). Con la entrada en vigor de este texto, los Estados parte ya no tienen excusas para eludir su obligación de socorrer a quienes huyen de la zona de conflicto. Los Estados deberán incorporar a sus ordenamientos jurídicos las disposiciones de la Convención, establecer un organismo gubernamental [apdo. 2.b) del art. 3] encargado de coordinar las actuaciones relacionadas con la protección y asistencia a los desplazados internos, poner en marcha estrategias y políticas sobre el desplazamiento forzado [apdo. 2.c) del art. 3], crear un sistema de alerta temprana (apdo. 2 del art. 4) o un sistema de registro de todos los desplazados internos (art. 13). Entre estas obligaciones y prohibiciones, cabe destacar la prohibición expresa de cualquier traslado arbitrario de personas o de un grupo de personas por parte de las autoridades [apdo. 1.a) del art. 3 y apdo. 4 del art. 4]. También prohíbe expresamente la exclusión o marginación de un colectivo para forzar su desplazamiento por los motivos ya indicados [apdo. 1.b) del art. 3]. Se reglamentan de un modo exhaustivo: se prevén las

МолাсA, B. E., Tesis doctoral titulada «El estatuto constitucional del desplazado interno en Colombia», Instituto de Derechos Humanos Bartolomé de las Casas, Doctorado en Derecho: programa de derechos humanos, 2007, Madrid (tesis no publicada), y ABRISKETA URIARTE, J., «La población internamente desplazada en Colombia: claves para interpretar la regulación internacional», Revista Electrónica de Estudios Internacionales, 2009, núm. 18, pp. 1-28. 
causas, se regulan todas las fases de los desplazamientos y se obliga a los Estados a incorporar el contenido esencial de la Convención de Kampala en su legislación interna.

La Convención de Kampala presenta un interesante mecanismo de control: pone en marcha un procedimiento regional de seguimiento de los progresos realizados al tiempo que proporciona información y buenas prácticas en la materia, de tal forma que las instituciones de la UA se convierten en autoridades esenciales para el cumplimiento del Convenio (art. 8). Se atribuye un papel especial de supervisión y cumplimiento de los objetivos de la Convención de Kampala a la Conferencia de los Estados miembros a la que hace referencia el art. 14.

Particularmente, es interesante subrayar que con la Convención de Kampala quedan bajo vigilancia todas las prácticas que persigan la apropiación ilegal de los recursos naturales [apdo. 1.i) del art. 3], un tema especialmente grave en la República Democrática del Congo, tal y como fue denunciado por el Consejo de Seguridad hace algún tiempo. Es un asunto que sigue atormentando a los desplazados internos y a los refugiados existentes al Este del país.

También entendemos que es especialmente destacable lo siguiente y un mecanismo que ofrece particular eficacia al sistema. Con este marco normativo, los tribunales de justicia pueden revelarse como los mayores defensores de los desplazados internos en el continente africano, pudiendo exigir responsabilidades individuales cuando se verifique que se ha presionado a un grupo de personas a huir de su lugar de residencia habitual. Este problema también afecta seriamente a otro país vecino de la República Democrática del Congo — Sudán-, lugar donde reina un vacío o la indiferencia de las autoridades gubernamentales ante la situación de los desplazados internos, con las carencias más elementales de medios en los campamentos y fuera de ellos, donde acaban hacinadas miles de personas, aunque en un principio su traslado a los campos fuera una solución transitoria. En la República Democrática del Congo, esta situación es particularmente lamentable por las dificultades para socorrer a los desplazados internos en peligro. En cierto modo, se pone el punto de mira en Ruanda, Burundi o Tanzania, principales lugares de tránsito en la exportación de minerales fuera de la República Democrática del Congo. También se procura combatir la violencia sexual, los saqueos, los secuestros y el reclutamiento de niños con fines militares o de otro tipo, etcétera.

La Convención de Kampala se revela como un motivo de esperanza para miles de desarraigados en situación de gran debilidad. Esperemos que este Tratado no quede en papel mojado, como una mera declaración de intenciones de los Gobiernos y de otros actores involucrados en el problema de los refugiados y de los desplazados internos. También es de esperar que se adhieran nuevos Estados especialmente afectados por la presencia en su territorio de desplazados internos. 


\section{RESUMEN}

\section{AVANCES Y MEJORAS DEL MARCO NORMATIVO PARA LA ASISTENCIA Y PROTECCIÓN DE LOS DESPLAZADOS INTERNOS EN ÁFRICA}

Entrar en el estudio de los desplazados internos tiene especial interés jurídico no sólo porque su número aumenta sin cesar, sino también porque su reglamentación jurídica todavía no está totalmente definida. Tras los esfuerzos de la Comunidad Internacional en la elaboración de los llamados Principios Rectores, hay que destacar al respecto la labor de la Conferencia Internacional de los Grandes Lagos y la adopción por la Unión Africana del nuevo Convenio de Kampala, vinculante y de ámbito continental.

Palabras clave: Desplazados internos, Principios Rectores, Conferencia Internacional de los Grandes Lagos, Unión Africana, Convenio de Kampala.

\section{ABSTRACT \\ PROGRESS AND IMPROVEMENT TOWARDS THE DEFINITION OF A LEGAL FRAMEWORK FOR THE ASSISTANCE AND PROTECTION OF INTERNALLY DISPLACED PERSONS IN AFRICA}

The study of internally displaced persons is of particular legal interest not only because their number is steadily increasing, but also because the legal framework is not yet fully defined. Following on from the international community's efforts to create the Guiding Principles, we highlight the importance of the work of the International Conference on the Great Lakes and the African Union's adoption of the Kampala Convention, which is binding for the entire continent.

Keywords: Internally Displaced, Guiding Principles, International Conference on Great Lakes Region, African Union, Kampala Convention.

\section{RÉSUMÉ}

\section{AVANCES ET AMÉLIORATIONS DU CADRE RÉGLEMENTAIRE POUR L'ASSISTANCE ET LA PROTECTION DES DÉPLACÉS INTERNES EN AFRIQUE}

L' approfondissement de l'étude des personnes déplacées présente un intérêt spécial du point de vue juridique, non seulement parce que leur nombre augmente continuellement, mais aussi parce que la régulation juridique n'est pas encore définie. Après des efforts de la communauté internationale pour l'élaboration des principes recteurs, il faut souligner le travail, à ce propos, aussi bien de la Conférence internationale des Grands Lacs que de l'Union africaine dans l'adoption de la nouvelle Convention de Kampala, obligatoire et d'application continentale.

Mots-clés: Déplacés internes, principes recteurs, Conférence internationale sur la Région des Grands Lacs, Union africaine, Convention de Kampala. 